\title{
Benzene oxygenation and oxidation by the peroxygenase of Agrocybe aegerita
}

\author{
Alexander Karich*, Martin Kluge, René Ullrich and Martin Hofrichter
}

\begin{abstract}
Aromatic peroxygenase (APO) is an extracellular enzyme produced by the agaric basidiomycete Agrocybe aegerita that catalyzes diverse peroxide-dependent oxyfunctionalization reactions. Here we describe the oxygenation of the unactivated aromatic ring of benzene with hydrogen peroxide as co-substrate. The optimum $\mathrm{pH}$ of the reaction was around 7 and it proceeded via an initial epoxide intermediate that re-aromatized in aqueous solution to form phenol. Identity of the epoxide intermediate as benzene oxide was proved by a freshly prepared authentic standard using GC-MS and LC-MS analyses. Second and third [per]oxygenation was also observed and resulted in the formation of further hydroxylation and following [per]oxidation products: hydroquinone and $p$-benzoquinone, catechol and o-benzoquinone as well as 1,2,4-trihydroxybenzene and hydroxy-p-benzoquinone, respectively. Using $\mathrm{H}_{2}^{18} \mathrm{O}_{2}$ as co-substrate and ascorbic acid as radical scavenger, inhibiting the formation of peroxidation products (e.g., p-benzoquinone), the origin of the oxygen atom incorporated into benzene or phenol was proved to be the peroxide. Apparent enzyme kinetic constants $\left(k_{c a t}, k_{m}\right)$ for the peroxygenation of benzene were estimated to be around $8 \mathrm{~s}^{-1}$ and $3.6 \mathrm{mM}$. These results raise the possibility that peroxygenases may be useful for enzymatic syntheses of hydroxylated benzene derivatives under mild conditions.
\end{abstract}

Keywords: Peroxidase, P450, Epoxide, Oxepin, Oxygen transfer

\section{Introduction}

Benzene is a poorly activated aromatic hydrocarbon that naturally occurs in crude oil. Worldwide it plays an important role as a most basic petrochemical (Fruscella 2000). Although it is not a common compound in the biosphere, some bacteria are able to metabolize benzene as sole carbon source. Pseudomonas putida converts it with a Rieske-type benzene 1,2-dioxygenase (EC 1.14.12.3) to benzene cis-dihydrodiol, which is also a side reaction catalyzed by toluene dioxygenase (EC 1.14.12.11) from the same bacterium. The former enzyme consists of three components, a flavoprotein reductase, a ferredoxin and a catalytic iron-sulfur protein (Bagnéris et al. 2005). Other bacteria produce soluble di-iron monooxygenases, for example, the four-component enzymes found under EC 1.14.13.-, some of which can oxidize benzene and other aromatics. Soluble methane monooxygenase (sMMO; EC 1.14.13.25) is an example of such a monooxygenase with exceptionally broad substrate spectrum (Colby et al. 1977;

\footnotetext{
* Correspondence: iualkari@ihi-zittau.de

Department of Bio- and Environmental Sciences, International Graduate School of Zittau, Markt 23, 02763, Zittau, Germany
}

Leahy et al. 2003; Tao et al. 2004; Zhou et al. 1999). In eukaryotes including humans, benzene is hydroxylated by cytochrome P450 monooxygenases (EC 1.14.14.1) using a similar reaction mechanism as the di-iron enzymes (Froland et al. 1992; Green and Dalton 1989; Seaton et al. 1994; Tamie and Rui-Sheng 1994).

A functional hybrid of monooxygenases and peroxidases is represented by a just recently accepted group of heme-thiolate proteins referred to as aromatic or unspecific peroxygenases (EC 1.11.2.1) (Hofrichter et al. 2010). The most detailedly studied member of this group is the Agrocybe aegerita aromatic peroxygenase (AaeAPO), which is secreted by an agaric fungus, the Black poplar mushroom. AaeAPO was found to catalyze a variety of oxyfunctionalization reactions such as hydroxylation of saturated hydrocarbons (Kluge et al. 2012; Peter et al. 2011; Ullrich and Hofrichter 2005), epoxidation of unsaturated hydrocarbons (Kluge et al. 2009; Kluge et al. 2012), heterocyclic $N$-oxidation (Ullrich et al. 2008), sulfoxidation (Aranda et al. 2009) and O-dealkylation (ether cleavages (Kinne et al. 2009b)). In contrast to the distantly related chloroperoxidase from Caldariomyces 
fumago (CPO; EC 1.11.1.10), APOs are able to peroxygenate/hydroxylate aromatic hydrocarbons, e.g. of toluene and naphthalene (Hofrichter et al. 2010). For the latter reaction, an epoxide intermediate was identified and the origin of the incorporated oxygen was proved to be the peroxide (Kluge et al. 2009). Earlier findings have given first indication that AaeAPO is also capable of oxidizing benzene but the underlying reaction has not been studied in detail, so far.

Whereas in all benzene oxygenations catalyzed by monooxygenases, the electron donor is $\mathrm{NAD}(\mathrm{P}) \mathrm{H}$ and the oxygen donor molecular oxygen $\left(\mathrm{O}_{2}\right)$, unspecific peroxygenases use hydrogen peroxide $\left(\mathrm{H}_{2} \mathrm{O}_{2}\right)$ as oxygen donor and electron acceptor. This and the fact that peroxygenases are stable extracellular enzymes make them an interesting biocatalytic tool both for basic studies on oxygen transfer reactions and biotechnological applications. Here we describe the peroxygenase-catalyzed, multiple hydroxylation of benzene that proceeds via the initial formation of benzene oxide.

\section{Materials and methods Chemicals and enzyme preparation}

All chemicals used were purchased from Sigma-Aldrich (Munich, Germany) with highest purity available except $\mathrm{H}_{2}^{18} \mathrm{O}_{2}$, which was obtained from Icon Isotopes (Summit, $\mathrm{NJ}$ ) and benzene oxide which was synthetized by a method similar to that used by Platt and Oesch (1977). In short, dibromination of 1,4-cyclohexadien with elemental $\mathrm{Br}_{2}$ in chloroform at $0^{\circ} \mathrm{C}$ led to 4,5 -dibromocyclohexene (van Tamelen 1955). The oxidation of 4,5-dibromocyclohexene leading to 4,5-dibromocyclohexene oxide was realized with $m$-chloroperoxybenzoic acid ( $m$ CPBA) (Gillard et al. 1991). Benzene oxide was formed by further dehydrobromination with diazobicyclo [5.4.0] undec-7-ene (DBU) mixed with acetonitrile (1:4). The $70 \mathrm{eV}$ mass spectra of the synthetized standard were largely identical to the mass spectra issued by Lovern et al. (1997).

$A$. aegerita aromatic peroxygenase (AaeAPO) was purified from cultures of $A$. aegerita strain TM-A1 (deposited at the Leibnitz institute DSMZ - German Collection of Microorganisms and Cell Cultures; collection number DSM 22459) by several steps of fast protein liquid chromatography (FPLC) as described previously (Ullich et al. 2004). The final enzyme preparation had a specific activity for veratryl alcohol of $83.7 \mathrm{U} \mathrm{mg}^{-1}$ and an $\mathrm{Rz}_{(420 / 277)}$ value (Reinheitszahl) of 1.3.

\section{Enzymatic reactions}

One-pot reaction mixtures contained $20 \mathrm{mM}$ potassium phosphate buffer of $\mathrm{pH} 3,4.5,6,7.5,9$ or 10.5 for evaluation, and $\mathrm{pH} 7$ for any other reaction setup. Substrate concentrations were $22.5 \mathrm{mM}$ for benzene and $0.5 \mathrm{mM}$ for phenol. For kinetic studies, benzene concentration was varied between $0.32 \mathrm{mM}$ and $5 \mathrm{mM}$. Every reaction mixture contained $1.56 \mu \mathrm{M}$ AaeAPO; for kinetic studies, this value was halved. The hydrogen peroxide $\left(\mathrm{H}_{2} \mathrm{O}_{2}\right)$ concentration routinely used in the reaction mixtures was $1 \mathrm{mM}$ and for kinetic studies $6 \mathrm{mM}$ (as a sum). In the first case, it was continuously added via a syringe pump over $30 \mathrm{~min}\left(1 \mu \mathrm{mol} \mathrm{h}{ }^{-1}\right)$. In the course of oxygen incorporation studies, benzene oxide experiments as well as kinetic studies, $\mathrm{H}_{2} \mathrm{O}_{2}$ was quickly added with a pipette (one-time addition of $1 \mathrm{mM}$ ). In kinetic studies, a mixture of $\mathrm{H}_{2} \mathrm{O}_{2}$ and benzene was used to start the reaction that was carried out in the presence of $5 \%(\mathrm{v} / \mathrm{v})$ acetonitrile. The final concentration of added ascorbic acid for the oxygen incorporation and kinetic studies was $4 \mathrm{mM}$ and $8 \mathrm{mM}$, respectively. All reactions were performed in HPLC vials in a final volume of $0.5 \mathrm{ml}$.

\section{High performance liquid chromatography (HPLC) and} liquid chromatography - mass spectrometry (LC-MS) HPLC analyses were performed with a 1200 Series Agilent system (Waldbronn, Germany) with diode-array $\mathrm{UV}$-vis detection. For reversed phase chromatographic separation, a Luna ${ }^{\circledR} 5 \mu \mathrm{m} \mathrm{C18} \mathrm{(2)} 100 \AA$ Å column (150 × $2 \mathrm{~mm}$, Phenomenex, Aschaffenburg, Germany) was used. The mobile phase consisted of (A) ammonium formate buffer (0.1\%; pH 3.6), and (B) acetonitrile. For the standard analysis, $5 \% \mathrm{~B}$ was held for $5 \mathrm{~min}$, then raised to $100 \% \mathrm{~B}$ within $17 \mathrm{~min}$ and held again for $3 \mathrm{~min}$. The analysis of samples containing benzene oxide was performed differently, i.e. by holding $20 \%$ B for 2 min, then raising up to $95 \% \mathrm{~B}$ within $7 \mathrm{~min}$ and holding this concentration for $1.5 \mathrm{~min}$. The spectra of eluting substances were recorded between 200 and $500 \mathrm{~nm}$.

After separation, the samples were also analyzed with an ion trap mass spectrometer (6300 Series, Agilent, Waldbronn, Germany). Ionization was achieved by atmospheric pressure chemical ionization (APCI) in the negative mode. Mass spectra were recorded in the range from 50 to $180 \mathrm{~m} / \mathrm{z}$.

\section{Gas chromatography - mass spectrometry (GC-MS)}

For the gas chromatographic detection of benzene oxide, the reaction mixture $(0.5 \mathrm{ml})$ was extracted with dichloromethane $(100 \mu \mathrm{l})$ and $1 \mu \mathrm{L}$ of the extract was analyzed with a GC-MS system (Agilent 6890 GC, 5973 MS, Waldbronn, Germany) equipped with a BPX5 capillary column $(30 \mathrm{~m} \times 0.25 \mathrm{~mm} \times 0.25 \mu \mathrm{m} \mathrm{FT}$; SGE Europe Ltd., Buckinghamshire, UK). The sample was injected with a split ratio of $5: 1$ at $250^{\circ} \mathrm{C}$. Initial oven temperature of $65^{\circ} \mathrm{C}$ was held for $1 \mathrm{~min}$ and then increased to $190^{\circ} \mathrm{C}$ at a rate of $45^{\circ} \mathrm{C} \mathrm{min}^{-1}$. Helium carrier gas was supplied at a rate of $1 \mathrm{ml} \mathrm{min}^{-1}$. 


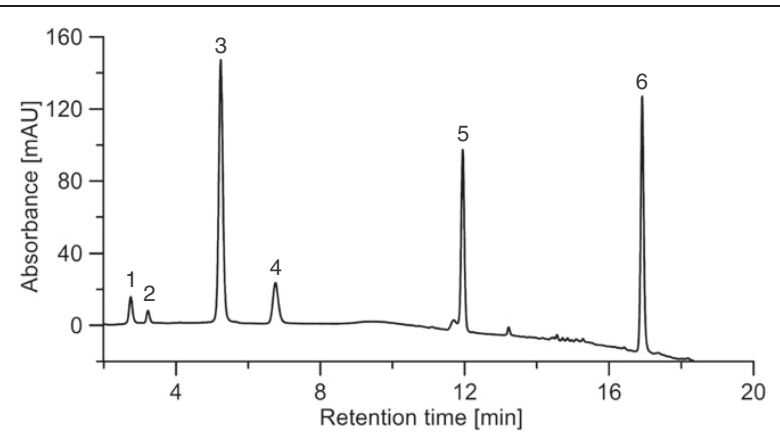

Figure 1 Reversed phase HPLC elution profile (recorded at $220 \mathrm{~nm}$ ) of benzene hydroxylation catalyzed by AaeAPO at $\mathrm{pH} 7.5$ with eluting products hydroquinone (1), hydroxy-pbenzoquinone (2), $p$-benzoquinone (3), catechol (4), and phenol (5); peak (6) refers to the substrate benzene.

\section{Further analytical methods}

To quantify the reaction products, calibration curves were prepared using authentic standards and the HPLC separation method described above. LC-MS analysis of both hydroquinone and $p$-benzoquinone gave anions of $108 \mathrm{~m} / z$ (the formation of the hydroquinone anion was already reported previously by (Letzel et al. 2001)). Catechol gave a $109 \mathrm{~m} / \mathrm{z}$ anion also previously observed (Albarran et al. 2010). As we did, the authors observed the same weight ion for the structurally related benzoquinones.

${ }^{18} \mathrm{O}$-Labeled hydrogen peroxide $\left(\mathrm{H}_{2}^{18} \mathrm{O}_{2}\right)$ was used as cosubstrate to prove the origin of the transferred oxygen. Peroxygenase-catalyzed incorporation of ${ }^{18} \mathrm{O}$ yielded isotopologue ions shifted by $2 \mathrm{~m} / z$ per incorporated oxygen.

Formation of the major products, i.e. the amounts of phenol, hydroquinone, catechol and $p$-benzoquinone formed during the reaction, was used for the estimation of kinetic data. Reaction conditions were the same as described above except that the benzene concentration was varied between $310 \mu \mathrm{M}$ and 5,000 $\mu \mathrm{M}$ and a smaller amount of AaeAPO $(0.78 \mu \mathrm{M})$ was used. Reactions were performed in triplicate, mixed with 2 parts of HPLCmobile phase (A) and injected, after $45 \mathrm{~s}$, into the HPLC system. The concentration of products was determined by HPLC as described above. Michaelis-Menten constant $\left(\mathrm{K}_{\mathrm{m}}\right)$ and catalytic constant $\left(\mathrm{k}_{\mathrm{cat}}\right)$ were obtained by nonlinear regression applying the Michaelis-Menten model in the ANEMONA program (Hernández and Ruiz 1998).

\section{Results}

\section{Products of benzene oxidation and effect of $\mathrm{pH}$}

By analyzing the products formed by AaeAPO from benzene with reversed phase HPLC, a spectrum of different hydroxylation and oxidation products was observed (Figure 1). Most important, the detection of phenol proved the difficult to accomplish [per] oxygenation/hydroxylation of benzene (Figure 2). Second hydroxylation was confirmed by detecting hydroquinone and catechol as well as their oxidation products $p$-benzoquinone (Figure 1) and $o$-benzoquinone (Figure 3 ), respectively. Figure 3 shows the UV-vis spectrum of a short-lived product found at low $\mathrm{pH}$ that resembles the spectrum of $o$ benzoquinone published by (Albarran et al. 2010). Third hydroxylation was proved by the detection of traces of 1,2,4-trihydroxybenzene and hydroxy- $p$-benzoquinone (Figure 1). All identified products co-eluted and shared their UV-vis spectra with authentic standards. Since there was no authentic benzene oxide standard available to prove the postulated initial epoxidation, benzene oxide was synthesized according to the method reported by Platt and Oesch (1977). Using this standard, the formation of benzene oxide was confirmed both by HPLC and GC-MS analyses (Figures 2 and 4).

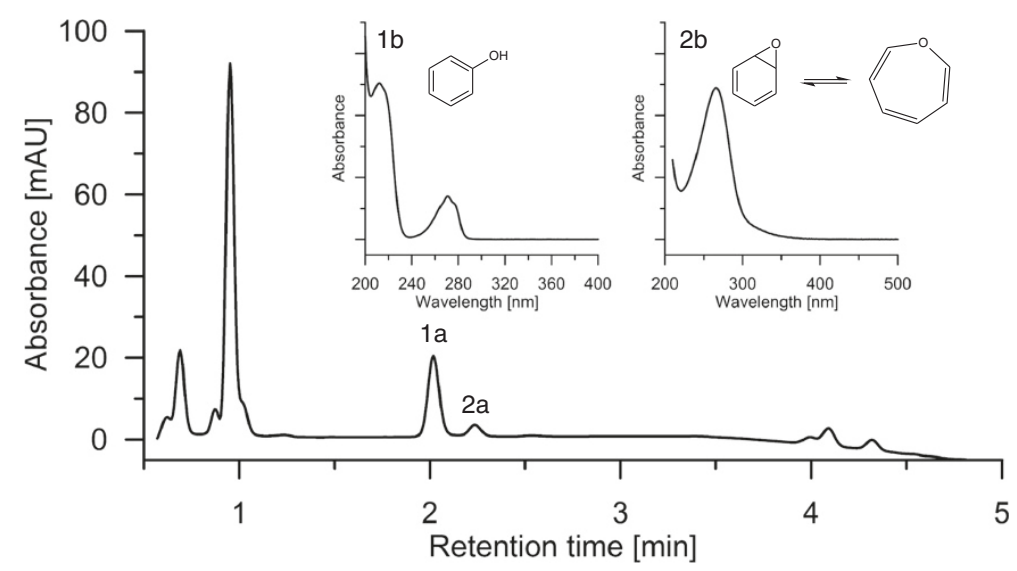

Figure 2 Reversed phase HPLC elution profile (recorded at $220 \mathrm{~nm}$ ) of a benzene sample treated with AaeAPO: phenol (1a) and benzene oxide (2a). The insets show the UV-vis spectra of phenol (1b), and benzene oxide (2b). 


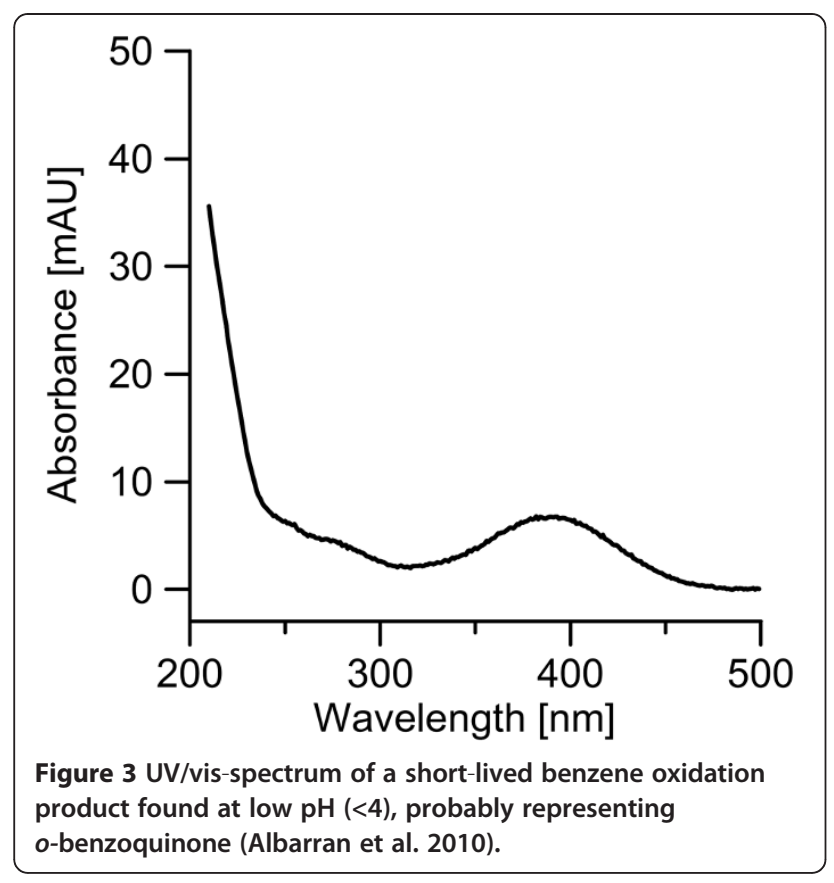

Coupling and polymerization of phenolic products formed was observed in all reactions without ascorbic acid and led to numerous small peaks eluting late from the HPLC column with unincisive UV-vis and mass spectra (data not shown).

Since benzene oxide, $o$-benzoquinone, trihydroxybenzene and hydroxyquinones were found only in traces $(<3 \mu \mathrm{M})$, just the concentrations of phenol, hydroquinone, catechol and $p$-benzoquinone were used to evaluate the effect of $\mathrm{pH}$ on the catalytic performance. Altogether, the formation of these major products (sum of them) showed a $\mathrm{pH}$ optimum around 7.5, although there were individual deviations from that for phenol and hydroquinone, in the case of which highest amounts were detectable at $\mathrm{pH} 10.5$ and 9 , respectively (Figure 5).

\section{Incorporation of oxygen}

${ }^{18} \mathrm{O}$-Labeled hydrogen peroxide $\left(\mathrm{H}_{2}^{18} \mathrm{O}_{2}\right)$ was used as probe to study the incorporation of oxygen into benzene and the isotopic distribution of ${ }^{18} \mathrm{O}$ in the products. Reactions were carried out with or without ascorbic acid as phenoxyl radical scavenger and analyzed by LC-MS. Mass spectra of catechol and $p$-benzoquinone but not of phenol were obtained by the LC-MS method used (Table 1). In the absence of ascorbic acid, we observed a substantial incorporation of ${ }^{18} \mathrm{O}$ originating from $\mathrm{H}_{2}^{18} \mathrm{O}_{2}$ in $p$-benzoquinone but not in catechol. In the presence of ascorbic acid, peroxygenation was detectable both for hydroquinone and catechol. The ratio of incorporated oxygen coming from the peroxide was higher in $p$-benzoquinone (or hydroquinone) than in catechol. The same trend was observed when phenol was used as substrate (Tab. 1); yet, the ratios of incorporated oxygen coming from hydrogen peroxide in both hydroquinone and catechol approached 100\% when ascorbic acid was used.

\section{Kinetic parameters for benzene hydroxylation}

Several facts hampered the exact determination of kinetic constants for benzene oxidation by AaeAPO. The HPLC method used required a preparation time of about $45 \mathrm{sec}$, which made a real-time/time-resolved analysis impossible. In addition, benzene is a highly volatile compound (tending to "crawl" along the glass and disappear that way from the reaction mixture), which made its decrease nearly unfeasible to determine exactly. Thus the formation of products had to be used for the estimation of kinetic data. However, when benzene is first converted into phenol, it immediately undergoes oxidation into further products, since phenol is a far better substrate than benzene.

Albeit the evaluation of benzene oxidation using the amount of different products formed describes an overall

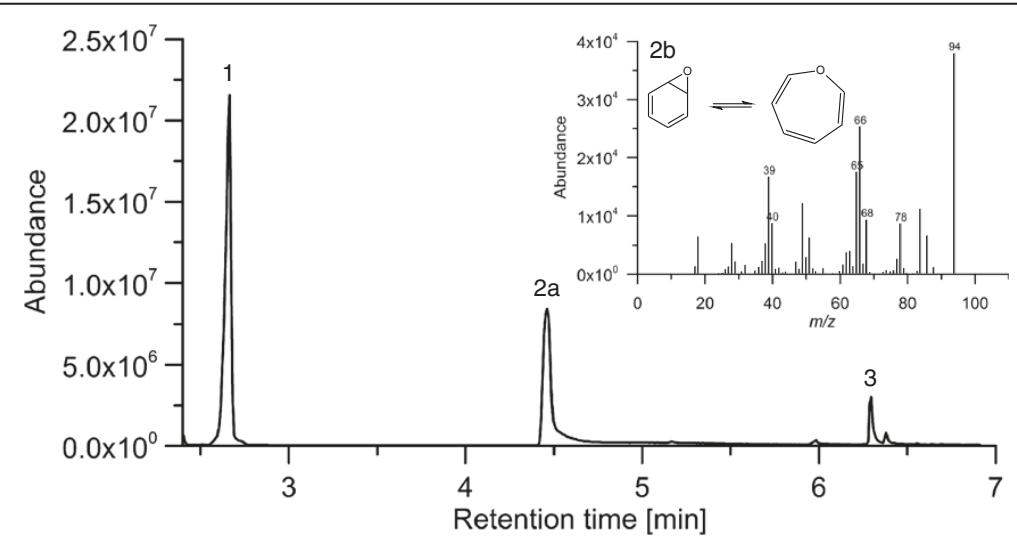

Figure 4 Gas chromatogram of a benzene sample treated with AaeAPO: benzene (1), benzene oxide (2a), and phenol (3). The inset (2b) shows the $70 \mathrm{eV}$ mass spectrum of benzene oxide obtained by LC-MS/MS. 


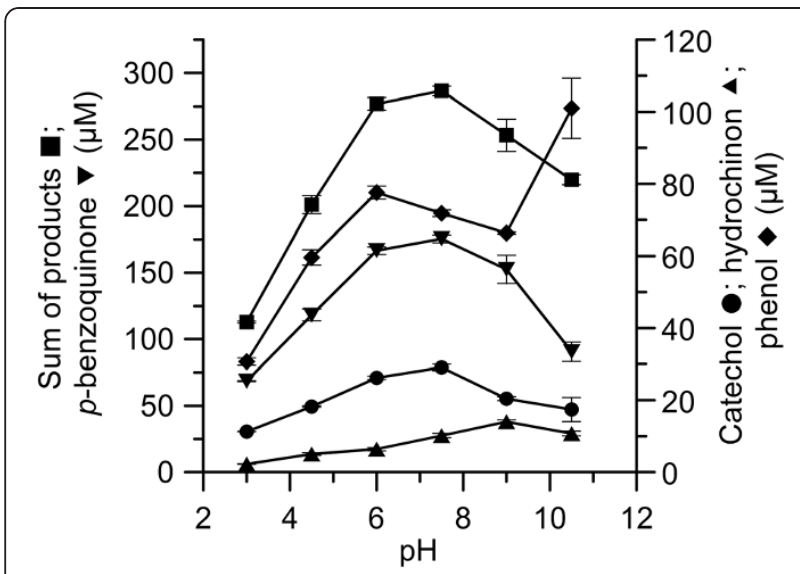

Figure $\mathbf{5}$ Effect of $\mathrm{pH}$ on the concentration of products formed in the course of benzene oxygenation/hydroxylation by AaeAPO.

reaction that includes several hydroxylation steps, this approach was found to be suitable to approximate the order of magnitude of kinetic values. Thus using the sum of the products phenol, hydroquinone, catechol and $p$-benzoquinone as measure, apparent kinetic constants $\left(\mathrm{k}_{\mathrm{cat}}, \mathrm{K}_{\mathrm{m}}\right)$ for benzene hydroxylation were estimated to be $8 \mathrm{sec}^{-1}$ and $3.6 \mathrm{mM}$ (Figure 6), and the resulting catalytic efficiency $2.2 \times 10^{3} \mathrm{M}^{-1} \mathrm{~s}^{-1}$.

\section{Discussion}

The variety of products formed in the course of benzene oxidation by AaeAPO reflects its ability to hydroxylate, in addition to benzene, also phenol and dihydroxybenzenes, which further undergo oxidation into quinones. It is reasonable that phenol represents a better substrate than the little activated benzene, because of the higher electron density at the aromatic ring. Thus phenol is oxidized by AaeAPO leading to peroxygenation/hydroxylation at para- or ortho-position to form hydroquinone or catechol. Since $p$-benzoquinone is the oxidation product of hydroquinone formed by AaeAPO in the peroxidase mode, the obtained data give evidence that para-hydroxylation is favored over ortho-hydroxylation. Formation of 1,2,4-trihydroxybenzene resulting from the hydroxylation either of

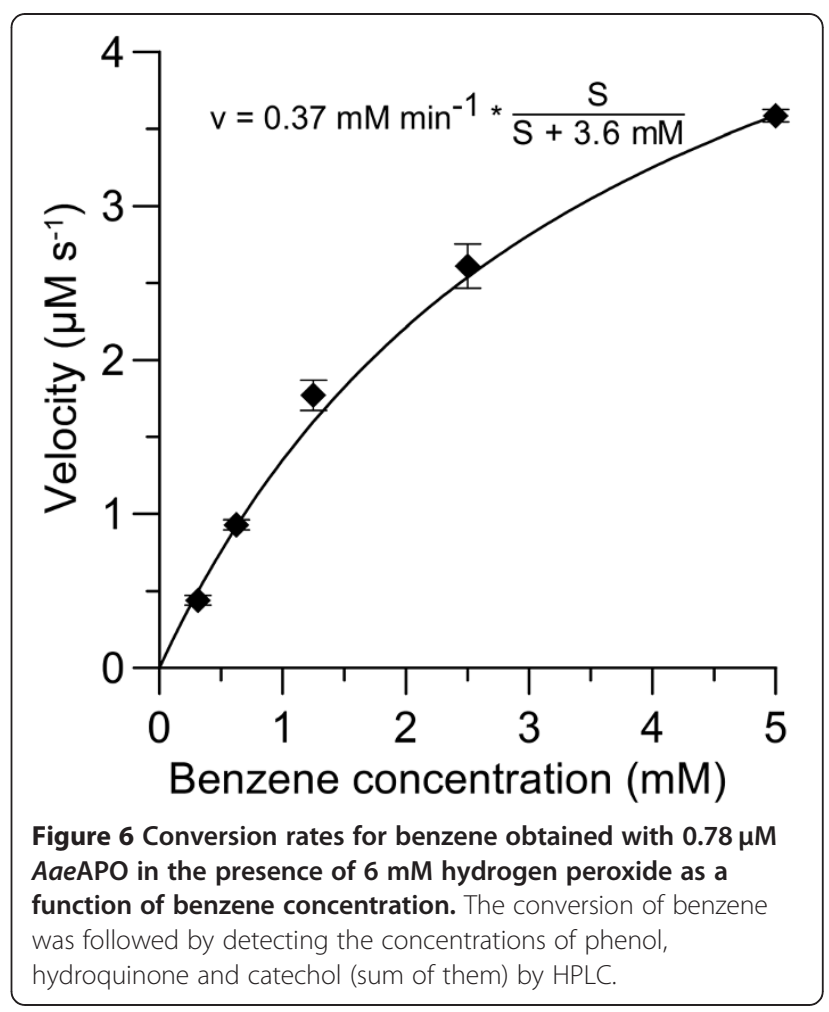

catechol or hydroquinone led to the conclusion that the reactions catalyzed by AaeAPO are, in contrast to toluene monooxygenase, more similar to the benzene metabolism by cytochrome $\mathrm{P} 450 \mathrm{~s}$ as proposed in previous reports (Snyder et al. 1993; Tao et al. 2004).

The $\mathrm{pH}$ optimum for the overall reaction was found to be around $\mathrm{pH}$ 7. That information fits well to earlier results concerning the $\mathrm{pH}$ optima of hydroxylations catalyzed by AaeAPO (Ullrich and Hofrichter 2005; Ullrich et al. 2004). The finding that the highest concentration of phenol was detectable at $\mathrm{pH} 10.5$ is a notable fact. A plausible explanation for that may be the $\mathrm{pK}_{\mathrm{a}}$ of phenol (9.9). At a $\mathrm{pH}$ value above the $\mathrm{pK}_{\mathrm{a}}$, a large portion $(>50 \%)$ of phenol is present as phenolate ion. The polar phenolate may not well be directed into the heme channel of the enzyme, which is lined with many non-polar phenylalanine residues (Piontek et al. 2010). Hence

Table 1 Origin of oxygen in the hydroxylation and oxidation products of benzene and phenol formed by AaeAPO in the presence of $\mathrm{H}_{2}^{18} \mathrm{O}_{2}$

\begin{tabular}{|c|c|c|c|c|c|c|c|c|c|}
\hline \multirow[t]{2}{*}{ Substrate } & \multicolumn{3}{|c|}{ Oxygen atoms in hydroquinone [rel.\%] } & \multicolumn{3}{|c|}{ Oxygen atoms in $p$-benzoquinone [rel.\%] } & \multicolumn{3}{|c|}{ Oxygen atoms in catechol [rel.\%] } \\
\hline & ${ }^{16} \mathrm{O} /{ }^{16} \mathrm{O}$ & ${ }^{16} \mathrm{O} /{ }^{18} \mathrm{O}$ & ${ }^{18} \mathrm{O} /{ }^{18} \mathrm{O}$ & ${ }^{16} \mathrm{O} /{ }^{16} \mathrm{O}$ & ${ }^{16} \mathrm{O} /{ }^{18} \mathrm{O}$ & ${ }^{18} \mathrm{O} /{ }^{18} \mathrm{O}$ & ${ }^{16} \mathrm{O} /{ }^{16} \mathrm{O}$ & ${ }^{16} \mathrm{O} /{ }^{18} \mathrm{O}$ & ${ }^{18} \mathrm{O} /{ }^{18} \mathrm{O}$ \\
\hline Benzene & n.d. ${ }^{\S}$ & n.d. ${ }^{\S}$ & n.d. ${ }^{\S}$ & 20 & 55 & 25 & 100 & 0 & 0 \\
\hline Benzene ${ }^{\#}$ & 9 & 25 & 66 & n.d. $\S^{\S}$ & n.d. ${ }^{\S}$ & n.d. ${ }^{\S}$ & 18 & 31 & 51 \\
\hline Phenol & 42 & 58 & 0 & 42 & 58 & 0 & 100 & 0 & 0 \\
\hline Phenol $^{\#}$ & 3 & 97 & 0 & n.d. ${ }^{\S}$ & n.d. ${ }^{\S}$ & $n \cdot d^{\S \S}$ & 6 & 94 & 0 \\
\hline
\end{tabular}

\# in presence of ascorbic acid (4 $\mathrm{mM})$.

$\$$ n.d. - not detectable, the concentration was too low to give a viable LC-MS signal.

$\S \S$ n.d. - not detected in the presence of ascorbic acid. 
phenol formed was hardly converted at a $\mathrm{pH}$ above its $\mathrm{pK}_{\mathrm{a}}$ and thus accumulated.

The analytical data of Figures 2 and 4 clearly show that the AaeAPO-catalyzed hydroxylation of benzene to phenol proceeds via a transient epoxide intermediate (benzene oxide that is in equilibrium with oxepin). This finding is in accordance with the results of naphthalene hydroxylation by AaeAPO, in the course of which also an unstable epoxide (naphthalene 1,2-oxide) was formed as first product (Kluge et al. 2009). Benzene hydroxylation by cytochrome P450 monooxygenases was reported to proceed via benzene oxide as well, but furthermore the direct hydroxylation to phenol or the oxygenation via a ketone intermediate (cyclohexenone) was proposed (Bathelt et al. 2008; de Visser and Shaik 2003). Since we did not find indications for the formation of the latter both intermediates, we assume that epoxidation is the major route of benzene peroxygenation by AaeAPO (compare also Barková et al. (2011) Kluge et al. (2009)).

The origin of incorporated oxygen in true peroxygenase reactions must be the peroxide. At first glance, this did not seemingly correspond well with the data found here using $\mathrm{H}_{2}^{18} \mathrm{O}_{2}$ as cosubstrate during benzene and phenol oxidation (Table 1). A plausible explanation for these results may be the ability of quinones to exchange their oxygen atoms with water (Fesenko and Gragerov 1955). The fact that $o$-benzoquinone is known to exchange its oxygen much faster with water than $p$-benzoquinone does, is reflected in the differences between the oxygen isotope distribution in $p$-benzoquinone (or hydroquinone) and catechol (Tab. 1). The formation of quinones was prevented by adding ascorbic acid to the reaction mixture, which led, in all cases, to an increase of the "heavy" oxygen isotope $\left({ }^{18} \mathrm{O}\right)$ in both hydroquinone and catechol (Tab. 1). Yet ascorbic acid did not inhibit the formation of quinones but instantly reduced them. Hence there was still a little moiety of the oxidized form that underwent oxygen exchange. That is why no product with $100 \%{ }^{18} \mathrm{O}$-incorporation was observed. Since ascorbic acid furthermore "blocks" the full peroxidase-mode of AaeAPO (one-electron oxidation) by reducing formed phenoxyl radicals, there was no other possibility for the oxidation of phenol than the peroxygenation (Kinne et al. 2009a). By blocking the peroxidasemode, also the further coupling of phenoxyl radicals was prevented (Figures 1 and 7).

The obtained kinetic constants for benzene hydroxylation by AaeAPO cannot be regarded as simply "apparent" with the applied reaction setup. That is because the analysis of the reaction products was realized by HPLC using the sum of four different products and therefore could not be run as real-time analysis. Different reactions occurred within the one and only reaction pot, e.g. the further hydroxylation of phenol. Nevertheless, the order of magnitude of the obtained kinetic constants may be helpful in evaluating the reaction. So the calculated catalytic efficiency $\left(\sim 2 \times 10^{3} \mathrm{M}^{-1} \mathrm{~s}^{-1}\right)$ for benzene peroxygenation by AaeAPO is rather low and in the same order of magnitude as the oxidation of pyridine that was also difficult to oxidize by AaeAPO (Ullrich et al. 2008). Hanioka described an apparent $K_{m}$ for benzene hydroxylation by a human cytochrome $\mathrm{P} 450$ monooxygenase that was with about $10 \mathrm{mM}$ three times higher than the value reported herein but still in the same order of magnitude (Hanioka et al. 2010).

The oxygenation/hydroxylation of benzene activates the molecule and thereby increases its biological accessibility by raising the solubility in water and the electron density of the ring (that is important in terms of biodegradability).

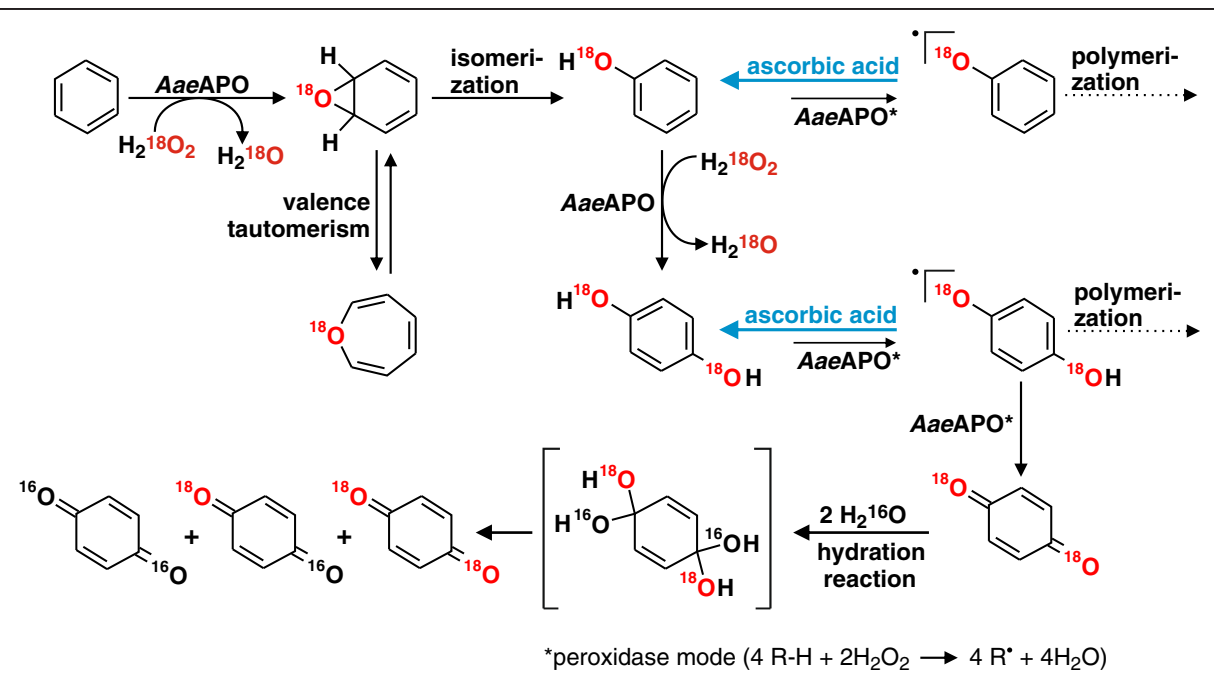

Figure 7 Hypothetic scheme for the epoxidation/hydroxlyation and further oxidation of benzene and its following products phenol and hydroquinone by AaeAPO; in the same way, catechol may be oxidized to o-benzoquinone. 
These effects apply to the second and third hydroxylation as well. Aerobic degradation of aromatic compounds via ring-cleavage of catechol derivatives leading to the formation of cis,cis-muconic acids and eventually of succinate and acetyl-CoA is a well-known metabolic pathway in many bacteria, and similar pathways are also present in fungi (Hofrichter et al. 1992; Jindrová et al. 2002; Sala-trepat and Evans 1971). Nevertheless benzene oxidation by a heme peroxidase/peroxygenase is reported herein for the first time. The first hydroxylation is the toughest-to-catalyze step and essential for the further degradation of the aromatic ring. Whether this reaction is involved in the co-metabolic oxidation of benzene by the whole fungus (A. aegerita), will have to be clarified in future physiological studies.

The enzymes characteristics described above suggest a certain application potential of peroxygenases in the preparation of hydroxylated benzene derivatives. Technical synthesis of phenol via the cumene process requires a large energy input and bears several environmental risks (Weber et al. 2000). Thus the environmental friendly production of phenol or further hydroxylated products by an enzymatic process would be a worthwhile approach. Furthermore chemical reactions opening the epoxide-ring of benzene oxide formed by peroxygenase could lead to specifically substituted phenols. Such ambitious goals, however, will necessitate much more research into the basics of peroxygenase catalysis and the heterologous expression of peroxygenases.

\section{Competing interests}

The authors declare that there are no competing interests.

\section{Acknowledgements}

The authors would like to thank the EU project PEROXICATS (KBBE-2010-4 265397) for financial support. We also thank S. Fränzle for helpful discussions and U. Schneider and M. Brand for technical support.

Received: 13 December 2012 Accepted: 14 January 2013

Published: 17 January 2013

\section{References}

Albarran G, Boggess W, Rassolov V, Schuler RH (2010) Absorption spectrum, mass spectrometric properties, and electronic structure of 1,2-benzoquinone. J Phys Chem A 114(28):7470-7478. doi:10.1021/jp101723s

Aranda E, Kinne M, Kluge M, Ullrich R, Hofrichter M (2009) Conversion of dibenzothiophene by the mushrooms Agrocybe aegerita and Coprinellus radians and their extracellular peroxygenases. Appl Microbiol Biotechnol 82(6):1057-1066. doi:10.1007/s00253-008-1778-6

Bagnéris C, Cammack R, Mason JR (2005) Subtle difference between benzene and toluene dioxygenases of Pseudomonas putida. Appl Environ Microbiol 71(3):1570-1580. doi:10.1128/aem.71.3.1570-1580.2005

Barková K, Kinne M, Ullrich R, Hennig L, Fuchs A, Hofrichter M (2011) Regioselective hydroxylation of diverse flavonoids by an aromatic peroxygenase. Tetrahedron 67(26):4874-4878. doi:10.1016/j.tet.2011.05.008

Bathelt CM, Mulholland AJ, Harvey JN (2008) QM/MM modeling of benzene hydroxylation in human cytochrome P450 2C9+. J Phys Chem A 112(50):13149-13156. doi:10.1021/jp8016908

Colby J, Stirling DI, Dalton H (1977) The soluble methane mono-oxygenase of Methylococcus capsulatus (Bath). Its ability to oxygenate n-alkanes, n-alkenes, ethers, and alicyclic, aromatic and heterocyclic compounds. Biochem J 165(2):395-402 de Visser SP, Shaik S (2003) A proton-shuttle mechanism mediated by the porphyrin in benzene hydroxylation by cytochrome P450 enzymes. J Am Chem Soc 125(24):7413-7424. doi:10.1021/ja034142f

Fesenko W, Gragerov IP (1955) Dokl Akad Nauk SSSR. 101:695

Froland WA, Andersson KK, Lee SK, Liu Y, Lipscomb JD (1992) Methane monooxygenase component $B$ and reductase alter the regioselectivity of the hydroxylase component-catalyzed reactions. A novel role for protein-protein interactions in an oxygenase mechanism. J Biol Chem 267(25):17588-17597

Fruscella W (2000) Benzene Kirk-Othmer Encyclopedia of Chemical Technology. John Wiley \& Sons, Inc

Gillard JR, Newlands MJ, Bridson JN, Burnell DJ (1991) $\pi$-Facial stereoselectivity in the Diels-Alder reactions of benzene oxides. Can J Chem 69(9):1337-1343. doi:10.1139/v91-199

Green J, Dalton H (1989) Substrate specificity of soluble methane monooxygenase. Mechanistic implications. J Biol Chem 264(30):17698-17703

Hanioka N, Yamamoto M, Tanaka-Kagawa T, Jinno H, Narimatsu S (2010) Functional characterization of human cytochrome P450 2E1 allelic variants: in vitro metabolism of benzene and toluene by recombinant enzymes expressed in yeast cells. Arch Toxicol 84(5):363-371. doi:10.1007/s00204-009-0504-1

Hernández A, Ruiz MT (1998) An EXCEL template for calculation of enzyme kinetic parameters by non-linear regression. Bioinformatics 14(2):227-228. doi:10.1093/bioinformatics/14.2.227

Hofrichter M, Günther T, Fritsche W (1992) Metabolism of phenol, chloro- and nitrophenols by the Penicillium strain $\mathrm{Bi} 7 / 2$ isolated from a contaminated soil. Biodegradation 3(4):415-421. doi:10.1007/bf00240363

Hofrichter M, Ullrich R, Pecyna M, Liers C, Lundell T (2010) New and classic families of secreted fungal heme peroxidases. Appl Microbiol Biotechnol 87(3):871-897. doi:10.1007/s00253-010-2633-0

Jindrová E, Chocová M, Demnerová K, Brenner V (2002) Bacterial aerobic degradation of benzene, toluene, ethylbenzene and xylene. Folia Microbiol (Praha) 47(2):83-93. doi:10.1007/bf02817664

Kinne M, Poraj-Kobielska M, Aranda E, Ullrich R, Hammel KE, Scheibner K, Hofrichter M (2009a) Regioselective preparation of 5-hydroxypropranolol and 4'-hydroxydiclofenac with a fungal peroxygenase. Bioorg Med Chem Lett 19(11):3085-3087. doi:10.1016/j.bmcl.2009.04.015

Kinne M, Poraj-Kobielska M, Ralph SA, Ullrich R, Hofrichter M, Hammel KE (2009b) Oxidative cleavage of diverse ethers by an extracellular fungal peroxygenase. J Biol Chem 284(43):29343-29349. doi:10.1074/jbc.M109.040857

Kluge M, Ullrich R, Dolge C, Scheibner K, Hofrichter M (2009) Hydroxylation of naphthalene by aromatic peroxygenase from Agrocybe aegerita proceeds via oxygen transfer from and intermediary epoxidation. Appl Microbiol Biotechnol 81(6):1071-1076. doi:10.1007/s00253-008-1704-y

Kluge M, Ullrich R, Scheibner K, Hofrichter M (2012) Stereoselective benzylic hydroxylation of alkylbenzenes and epoxidation of styrene derivatives catalyzed by the peroxygenase of Agrocybe aegerita. Green Chem 14(2):440-446

Leahy JG, Batchelor PJ, Morcomb SM (2003) Evolution of the soluble diron monooxygenases. FEMS Microbiol Rev 27(4):449-479. doi:10.1016/s0168-6445 (03)00023-8

Letzel T, Pöschl U, Wissiack R, Rosenberg E, Grasserbauer M, Niessner R (2001) Phenyl-modified reversed-phase liquid chromatography coupled to atmospheric pressure chemical ionization mass spectrometry: A universal method for the analysis of partially oxidized aromatic hydrocarbons. Anal Chem 73(7):1634-1645. doi:10.1021/ac001079t

Lovern MR, Turner MJ, Meyer M, Kedderis GL, Bechtold WE, Schlosser PM (1997) Identification of benzene oxide as a product of benzene metabolism by mouse, rat, and human liver microsomes. Carcinogenesis 18(9):1695-1700. doi:10.1093/carcin/18.9.1695

Peter S, Kinne M, Wang X, Ullrich R, Kayser G, Groves JT, Hofrichter M (2011) Selective hydroxylation of alkanes by an extracellular fungal peroxygenase. FEBS J 278(19):3667-3675. doi:10.1111/j.1742-4658.2011.08285.x

Piontek K, Ullrich R, Liers C, Diedrichs K, Plattner AD, Hofrichter M (2010) Crystallization of a $45 \mathrm{kDa}$ peroxygenase/peroxidase from the mushroom Agrocybe aegerita and structure determination by SAD utilizing only the haem iron. Acta Crystallograph Sect F Struct Biol Cryst Commun 66:693-698. doi:10.1107/S1744309110013515

Platt KL, Oesch F (1977) The preparation of [14C] and [3H] labelled benzene oxide. J Labelled Compd Radiopharm 13(4):471-479. doi:10.1002/ jlcr.2580130403

Sala-trepat JM, Evans WC (1971) The meta cleavage of catechol by Azotobacter species. Eur J Biochem 20(3):400-413. doi:10.1111/j.1432-1033.1971.tb01406.x 
Seaton MJ, Schlosser PM, Bond JA, Medinsky MA (1994) Benzene metabolism by human liver microsomes in relation to cytochrome P450 2E1 activity. Carcinogenesis 15(9):1799-1806. doi:10.1093/carcin/15.9.1799

Snyder R, Chepiga T, Yang CS, Thomas H, Platt K, Oesch F (1993) Benzene metabolism by reconstituted cytochromes P450 2B1 and 2E1 and its modulation by cytochrome b5, microsomal epoxide hydrolase, and glutathione transferases: evidence for an important role of microsomal epoxide hydrolase in the formation of hydroquinone. Toxicol Appl Pharmacol 122(2):172-181. doi:10.1006/taap. 1993.1185

Tamie N, Rui-Sheng W (1994) Induction of cytochrome P450 by toluene. Int J Biochem 26(12):1333-1340. doi:10.1016/0020-711x(94)90175-9

Tao Y, Fishman A, Bentley WE, Wood TK (2004) Oxidation of benzene to phenol, catechol, and 1,2,3-trihydroxybenzene by toluene 4-monooxygenase of Pseudomonas mendocina KR1 and toluene 3-monooxygenase of Ralstonia pickettii PKO1. Appl Environ Microbiol 70(7):3814-3820. doi:10.1128/ aem.70.7.3814-3820.2004

Ullrich R, Dolge C, Kluge M, Hofrichter M (2008) Pyridine as novel substrate for regioselective oxygenation with aromatic peroxygenase from Agrocybe aegerita. FEBS Lett 582(29):4100-4106. doi:10.1016/j.febslet.2008.11.006

Ullrich R, Hofrichter M (2005) The haloperoxidase of the agaric fungus Agrocybe aegerita hydroxylates toluene and naphthalene. FEBS Lett 579(27):6247-6250. doi:10.1016/j.febslet.2005.10.014

Ullrich R, Nüske J, Scheibner K, Spantzel J, Hofrichter M (2004) Novel haloperoxidase from the agaric basidiomycete Agrocybe aegerita oxidizes aryl alcohols and aldehydes. Appl Environ Microbiol 70(8):4575-4581. doi:10.1128/ aem.70.8.4575-4581.2004

van Tamelen EE (1955) The reaction of cyclohexadiene-1,4 with electrophilic reagents. J Am Chem Soc 77(6):1704-1706. doi:10.1021/ja01611a105

Weber M, Weber M, Kleine-Boymann M (2000) Phenol Ullmann's Encyclopedia of Industrial Chemistry. Wiley-VCH Verlag GmbH \& Co, KGaA

Zhou N-Y, Jenkins A, Chan Kwo Chion CKN, Leak DJ (1999) The alkene monooxygenase from Xanthobacter strain Py2 is closely related to aromatic monooxygenases and catalyzes aromatic monohydroxylation of benzene, toluene, and phenol. Appl Environ Microbiol 65(4):1589-1595

doi:10.1186/2191-0855-3-5

Cite this article as: Karich et al.: Benzene oxygenation and oxidation by the peroxygenase of Agrocybe aegerita. AMB Express 2013 3:5.

\section{Submit your manuscript to a SpringerOpen ${ }^{\circ}$ journal and benefit from:}

- Convenient online submission

- Rigorous peer review

- Immediate publication on acceptance

- Open access: articles freely available online

- High visibility within the field

- Retaining the copyright to your article

Submit your next manuscript at $>$ springeropen.com 